\title{
Tendências do setor postal \\ no cenário internacional: liberalização, regulação do mercado e reestruturação organizacional
}

Tadeu Gomes Teixeira*

\begin{abstract}
Resumo: O objetivo deste artigo é analisar as tendências do sistema postal no cenário internacional com foco nos mecanismos de regulação do mercado e nos processos de reestruturação dos modelos organizacionais dos operadores públicos rumo à corporatização e privatização, evidenciando os impactos sobre a esfera do trabalho. $\mathrm{O}$ artigo foi realizado por meio de uma pesquisa documental e bibliográfica e dados secundários da União Postal Universal. Foram compilados e analisados relatórios produzidos por organismos multilaterais e blocos regionais. Dentre as principais conclusões, verifica-se a liberalização dos mercados postais como tendência predominante associada a processos graduais de concentração de mercado e consequente formação de oligopólios, sobretudo por grupos transnacionais. A liberalização postal tem sido acompanhada de processos de reestruturação organizacional e privatização dos operadores estatais sob a justificativa da modernização gerencial. Além disso, constatam-se processos de reestruturação operacional e, concomitantemente, precarização do trabalho e crescente redução dos postos de trabalho no setor.
\end{abstract}

Palavras-chave: sistemas de correios, liberalização postal, regulação, reestruturação organizacional, redução de postos de trabalho.

\section{Introdução}

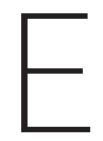

m matéria veiculada no dia 18 de janeiro de 2014, o jornal O Estado de S. Paulo noticiou prejuízos da Empresa Brasileira de Correios e Telégrafos (ECT) no segmento de cartas no exercício de 2013. O jornal aproveitou o ensejo para analisar aspectos de uma suposta crise na estatal brasileira e apontar possíveis soluções: "Em crise, serviços postais recorrem à privatização", citando diversos casos de privatização dos operadores estatais de correios em vários países (Matais, 2014).

O jornal se referia às transformações por que vem passando os sistemas postais ${ }^{1}$ no continente europeu, mas também observáveis no asiático e americano desde o final da década de 1980, apontando um possível caminho para o sistema postal brasileiro. Trata-se de um processo que tem alterado a organização, estrutura, regulação e organização do trabalho dos operadores postais públicos e privados em todo o mundo (Crew \& Kleindorf, 2005). Mas quais são as características dessas mudanças?
Recebido: 13.03 .14

Aprovado: 22.05.15

\footnotetext{
* Professor da Universidade Federal do Maranhão e doutor em ciências sociais pela Universidade Estadual de Campinas.<tagote@gmail. com>.

1. A Organização para Cooperação e Desenvolvimento Econômico (OCDE) define os serviços postais como "[...] forma particular de serviços de transporte e comunicação para entrega de bens e/ ou informações de um ponto a outro, mesmo que no exercício dessa função os operadores postais tenham que competir com outras empresas de entrega e, principalmente, com os serviços de telecomunicações" (OCDE, 1999: 7, tradução nossa).
} 
O objetivo deste artigo é responder a essa questão a partir de uma análise das transformações postais no cenário internacional por meio de casos selecionados. Trata-se, portanto, de uma análise parcial que busca acompanhar as direções das mudanças, tendo como foco investigativo os processos de regulação do mercado, a reestruturação organizacional objetivando a corporatização e a privatização dos operadores estatais e a indicação de como esses processos repercutem na esfera do trabalho neste setor.

O artigo foi desenvolvido com base em uma análise documental e bibliográfica na qual foram verificados e analisados relatórios elaborados por agências multilaterais como o Banco Mundial, a União Postal Universal e blocos regionais como a União Europeia. Nesse sentido, analisaram-se o relatório do Projeto Piquet da Comissão Europeia, elaborado por Torsten Brandt (2007), que buscou analisar o impacto das privatizações naquele continente a partir de uma análise sobre o emprego, a produtividade e a qualidade dos serviços; o relatório pioneiro do Banco Mundial, preparado com apoio da União Postal Universal, publicado em 1996 (Ranganathan \& Dey, 1996); os relatórios da European Comission sobre o setor postal (PLS Randoll, 2002; Brandt, 2007) e da European Foundation for the Improvement of Living and Working Condition (Eurofound, 2007), órgãos da União Europeia, além de publicações da OCDE e estudos encomendados por confederação sindical internacional que representa mais de novecentos sindicatos em todo o mundo (Uni Global Union, 2009). Tais relatórios, dessa forma, são fontes primárias de informação. Além das fontes primárias, fontes secundárias e bibliográficas também foram consultadas e estão referenciadas no texto, bem como informações da União Postal Universal. A análise temática a partir de categorias significantes - regulação, modelo organizacional, liberalização, trabalho - orientou a análise das informações.

Além desta introdução e das considerações finais, o artigo está dividido em quatro seções. Na primeira, analisam-se as etapas das transformações no mercado postal internacional com foco nos processos gradativos de liberalização e nos mecanismos de regulação do mercado postal. Em seguida, verificam-se quais foram as etapas seguidas na União Europeia no processo de transformação dos sistemas postais. Na terceira parte, discutem-se as mudanças nos modelos organizacionais e os processos de corporatização e privatização dos operadores postais públicos. Por fim, analisam-se as articulações da mudança com as transformações na esfera do trabalho, mormente os processos de reestruturação operacional e redução dos postos de trabalho. 


\section{Liberalização e regulação dos mercados, corporatização e privatização dos operadores públicos: etapas da transformação nos sistemas postais}

Os sistemas de correios estiveram, de maneira geral, vinculados aos Estados nacionais. A regulação do setor postal baseou-se, até o final do século passado e nos mais diversos países, no monopólio de serviços e na exclusividade de um operador estatal. Desde as primeiras décadas do século XX, os departamentos ou órgãos de correios de propriedade estatal estruturaram-se em grandes corporações verticalizadas e integradas (Crew \& Kleindorf, 2005).

Os motivos alegados para as mudanças na regulação do setor postal e as diretrizes que deviam ser seguidas foram mais bem formulados e disseminados por agências multilaterais como o Banco Mundial e o Fundo Monetário Internacional.

Em um relatório do Banco Mundial, preparado com o auxílio da União Postal Universal (UPU) e publicado em 1996 - intitulado Redirecting mail: postal sector reform - foram apresentadas as razões pelas quais as administrações postais deviam ser transformadas e quais os caminhos a seguir. Dentre elas, o Banco Mundial listou a suposta ineficiência e inadequação dos operadores públicos às necessidades do mercado e da população. Os correios estatais - na visão do Banco Mundial - não proporcionavam rentabilidade nem mesmo para investimentos na melhoria dos serviços, o que teria motivado diferentes governos a buscar reformas para o setor (Ranganathan \& Dey, 1996).

Nesse sentido, a Organização para Cooperação e Desenvolvimento Econômico (OCDE) argumenta:

\footnotetext{
A contínua desregulamentação e liberalização dos outros setores da economia demonstraram os benefícios da competição na meIhoria da qualidade, eficiência, inovação e redução dos preços aos consumidores, o que tem destacado a incongruência do monopólio e das restrições para operação nesse setor (OCDE, 1999: 21, tradução nossa).
}

Diante disso, verifica-se que as transformações no setor postal no cenário internacional estão vinculadas à hegemonia do neoliberalismo a partir da década de 1980 . O neoliberalismo, encampado por organismos multilaterais como o Banco Mundial e o Fundo Monetário Internacional (FMI), propunha um receituário que se tornou conhecido, sobretudo na América Latina, como "Consenso de Washington", cujas práticas desencadeariam a liberalização dos mercados nacionais, processos de privatização, livre circulação de capitais financeiros e a reformulação das responsabi- 
lidades do Estado, que deveriam centrar-se na manutenção da livre competição e estabilização econômica, na redução dos investimentos sociais e desoneração fiscal dos ricos e na desregulamentação dos direitos trabalhistas, o que quase sempre desconsiderava a força de trabalho, a proteção social e os interesses públicos (Harvey, 2007; Antunes, 2004; Castel, 1999; Anderson, 1995).

Além do neoliberalismo, o avanço do desenvolvimento tecnológico também é relevante para se compreender as transformações no setor postal, seja como inovação nos meios de comunicação, seja apenas como argumento ideológico. As transformações tecnológicas apareceram nos argumentos dos organismos multilaterais de forma ideológica e determinista. Segundo eles,

o desenvolvimento tecnológico e em especial o das telecomunicações (por meio do fax, telefone, e-mail, internet etc.) estão erodindo o "coração do negócio" dos sistemas de correios tradicionais, com potencial para ameaçar sua capacidade em continuar financiando as obrigações sociais com os serviços universais (OCDE, 1999: 21, tradução nossa).

Nessa mesma linha, o Banco Mundial já havia afirmado, em 1996, que as tecnologias de informação eram responsáveis pela "necessidade" de liberalizar os mercados postais; tais argumentos, todavia, escondiam, por exemplo, o interesse de empresas de courier nos mercados nacionais e a pressão que exerciam pela liberalização postal (Ranganathan \& Dey, 1996).

Os projetos de reorganização do setor postal, assim, buscaram também atender aos interesses de operadores postais privados (empresas de courier), pois, como argumentaram os técnicos da OCDE (1999), o crescimento das empresas no mercado postal aberto à competição tem sido limitado em razão dos correios estatais ainda terem "privilégios" nas operações.

O argumento ideológico é bem distinto do fenômeno associado à diminuição do fluxo de comunicação pessoal - cartas entre pessoas - que representa um pequeno percentual no fluxo dos objetos postais. Ao mesmo tempo, o então diretor da União Postal Universal destacou que o mercado para transporte de mercadorias tem crescido muito com o processo de globalização (Leavey, 1996). Há, portanto, um impacto tecnológico sobre o setor que tem alterado a composição do mercado postal com a redução do volume de correspondências e, concomitantemente, um aumento no volume de encomendas e serviços expressos.

Isso significa, em suma, que as mudanças tecnológicas não afetaram o volume e o tráfego postal, embora tenha ocorrido uma mudança na natureza dos objetos pos- 
tais, sobretudo com o incremento de postagens vinculadas às atividades comerciais. As transformações na tecnologia informacional, assim, podem ser situadas a partir de seu impacto no volume, fluxo e tipos de serviços prestados.

Na análise proposta pelo Banco Mundial, havia a necessidade imediata de reforma postal, sobretudo nos países em desenvolvimento. E isso seria justificado porque o setor estaria ineficiente e insustentável, onerando os cofres públicos para cobrir déficits de operação. Para a agência, o setor sofria para manter as operações, que se tornavam cada vez mais obsoletas e ineficientes ao ponto de prejudicar o desenvolvimento de atividades econômicas que utilizavam a infraestrutura dos serviços postais (Ranganathan \& Dey, 1996).

A alegada necessidade de reforma do setor postal deveria ser assumida e implantada como projeto de governo - segundo o Banco Mundial -, sem deixar que "ideias tradicionais" limitassem os objetivos e esforços das reformas (Ranganathan \& Dey, 1996). Tais reformas, segundo a proposta da agência, deveriam compor um programa compreensível e integrado a ser seguido "imediatamente", sobretudo com a introdução de mecanismos de gestão alinhados à lógica de mercado.

As reformas deveriam ser acompanhadas por mudanças nos mecanismos de regulação do setor. Até 1996, a maioria dos países mantinha o monopólio postal ou algum tipo de reserva de mercado. Para o Banco Mundial, a liberalização do mercado era importante para garantir a atuação dos operadores privados sem restrições.

Com isso, o quadro que até então só contava praticamente com a presença de instituições governamentais no financiamento e na gestão do setor postal seria alterado, o que supostamente garantiria mais eficiência e qualidade. Tais diagnósticos e propostas, portanto, tinham como premissa o pressuposto neoliberal da eficiência do mercado na alocação de recursos.

Com base nesse ideário, em 1999 os países membros da OCDE se reuniram para debater os rumos do setor. À mesa de discussões foi dado um sugestivo nome: "Promoting competition in postal services". O objetivo, como está explícito na denominação do fórum, foi debater e propor medidas para estimular e promover a competitividade nos serviços postais. Por competitividade entendia-se a abertura dos mercados nacionais com a quebra de monopólio dos operadores públicos e, de preferência, com a privatização das entidades estatais.

Segundo a OCDE, apesar de iniciativas de desregulamentação de diversos segmentos da economia, o mesmo não acontecera com o setor postal. Diante disso, o Banco Mundial chegou a afirmar que 
2. O fato de o governo dos Estados Unidos manter uma reserva de mercado e uma empresa pública - United States Postal Services - atuante no setor com quase $700 \mathrm{mil}$ funcionários, mesmo com a crise financeira por que passa o setor naquele país, endossa os argumentos acerca da inexistência de consenso sobre as mudanças na área. enquanto significativos progressos em termos de reforma são realizados em outros setores do serviço público, o setor postal é um dos últimos bastiões da antiga ordem (OCDE, 1999: 21, tradução nossa).

É relevante o fato de só em 1999 os países da OCDE terem se reunido para debater as transformações postais. O fato de os correios estatais terem passado incólumes pelos processos de privatização que ocorreram nos anos de 1980 e 1990 na Europa e nos Estados Unidos ${ }^{2}$ já indica o setor é "politicamente delicado", como afirmam Luisa Anderloni e Roberto Pilley (2002).

A OCDE (1999) apontou como necessário ao processo de reforma postal:

a. eliminar o monopólio dos correios estatais;

b. propiciar a abertura de mercado; e

c. criar condições para que os serviços obrigatórios de correio fossem assegurados.

O monopólio postal tem sido justificado, segundo Luisa Anderloni e Roberto Pilley (2002), por prover as condições para sustentação de uma estrutura de custos capaz de satisfazer as necessidades de um mercado interno com preços abaixo dos praticados em mercados abertos. Na maioria dos países membros da OCDE (1999), as empresas estatais asseguram o monopólio de certos segmentos do mercado postal. Esse monopólio é definido pelo preço ou peso de determinados serviços postais ou pela combinação de ambos. O objetivo do monopólio é subsidiar o custo dos serviços não comerciais prestados para entrega das correspondências em áreas de baixo retorno financeiro para as companhias.

Para a OCDE (1999), as restrições e monopólios deveriam ser eliminados porque gerariam uma suposta distorção no mercado ao favorecer o operador postal estatal. Segundo a organização, as áreas que precisassem de atendimento especial seriam cobertas mediante uma melhor alocação dos recursos pelos operadores privados. O mercado competitivo - sustentam os técnicos da organização - encontraria a solução para "esse problema" (sic). Novamente, o pressuposto da eficiência da livre competição, associado aos interesses de empresas de courier, compõem os argumentos das agências responsáveis por disseminar as propostas neoliberais.

Contudo, o sistema postal precisa ser realizado em toda a extensão dos territórios nacionais e a custos razoáveis, o que nem sempre segue a lógica de mercado. As empresas postais privadas não funcionam com tal preocupação social, isto é, se a população de uma determinada região está sendo atendida de forma satisfatória a despeito do lucro. 
Sendo assim, a lógica dos operadores privados - maximização dos lucros - e a necessidade de atender a população não são convergentes, tornando-se um aspecto problemático para os defensores da liberalização (Anderloni \& Pilley, 2002). Assim, os serviços não comerciais justificariam a manutenção da reserva de mercado. No entanto, onde a liberalização ganhou terreno cogita-se a criação de fundos com a contribuição dos operadores do mercado, públicos ou privados, para viabilizar as perdas decorrentes do atendimento às áreas não comerciais.

Juntamente com a liberalização do mercado - argumentam os representantes da $\mathrm{OCDE}$-, seria preciso eliminar as barreiras à competitividade do setor postal, como as vantagens que os operadores estatais detêm, a exemplo das isenções fiscais.

As transformações nos sistemas de correios abarcavam, portanto, propostas para:

1. liberalização postal e quebra de monopólios;

2. criação de novas formas de regulação para o setor; e

3. corporatização e privatização dos correios estatais.

À vista disso, são medidas alinhadas às diretrizes do Consenso de Washington, propostas para desregulamentação dos mercados e privatização de empresas estatais.

O programa de reformas a ser implantado nos sistemas de correios deveria incluir crescentes reestruturações organizacionais - segundo o Banco Mundial -, isto é, "reformas empresariais" capazes de melhorar a eficiência e melhorar os serviços (Ranganathan \& Dey, 1996). Assim, as "reformas empresariais" são adotadas para redirecionar as ações dos operadores postais à lógica de mercado, ou seja, consiste na adoção de princípios empresariais para gestão da organização postal.

Um passo adiante no processo é a "corporatização" (corporatization). O processo consiste na transformação de um órgão da administração pública direta - departamento, autarquia ou outro órgão de Estado - em corporação; a princípio, em uma empresa pública. Assim, trata-se de um processo que objetiva modificar os instrumentos legais para transformação jurídica dos correios estatais em empresas, desvinculando as entidades do poder público direto e garantindo autonomia gerencial e funcionamento com base no direito privado e empresarial mesmo quando o poder público continua a ser o proprietário ou acionista majoritário. Trata-se, portanto, de reformas organizacionais concatenadas à reestruturação dos modelos empresariais (Castells, 2005), uma das faces, portanto, dos processos de reestruturação produtiva (Antunes, 1999).

Ao observar e analisar os rumos das transformações postais nos países da OCDE, Luisa Anderloni e Roberto Pilley (2002) argumentam que as privatizações no setor 
têm seguido uma processualidade, o que é corroborado por relatório da Comissão Europeia (Brandt, 2007) na sistematização das transformações nos países daquele continente. Ao considerar que os operadores postais são inicialmente vinculados a ministérios ou departamentos de Estado, os passos no sentido da privatização têm sido transformá-los em empresas públicas com capital estatal, sociedades de economia mista com o Estado como sócio majoritário, sociedades de economia mista com ações preferenciais, sociedades anônimas majoritariamente de capital privado e, finalmente, a privatização total. Todavia, algumas "medidas de privatização" são encontradas no setor mesmo antes da privatização completa das entidades, como a transferência da rede de atendimento a terceiros por meio de franquias ou outros mecanismos contratuais; processo de terceirização de agências adotado no Brasil desde o final da década de 1980 (Teixeira, 2013).

\section{O processo gradual de liberalização postal na União Europeia}

Os serviços postais na União Europeia distribuem cerca de 135 bilhões de objetos postais por ano, com uma estimativa de lucro em torno de $€ 90$ bilhões, o que equivale a $1 \%$ do produto interno bruto (PIB) do bloco, conforme informações oficiais de 2013 (Postal Services, 2013).

Os princípios básicos da União Europeia pressupõem a livre competição e a ausência de barreiras comerciais entre os países membros. Nesse sentido, enquanto nos demais setores a ideologia neoliberal atuou fortemente no processo de liberalização devido à convergência de objetivos - tornando-a uma opção política legitimada entre os agentes governamentais -, o setor postal europeu vem passando por uma liberalização impulsionada também pelos princípios e arranjos de integração regional.

Segundo Luisa Anderloni e Roberto Pilley (2002) e a Comissão Europeia (Brandt, 2007), os serviços postais na Europa eram prestados diretamente pelos Estados nacionais no início da década de 1980, a exemplo da prestação realizada pelos serviços de telecomunicações.

3. O Green paper é um documento utilizado na União Europeia para suscitar debates em torno de um tema. Pode subsidiar, posteriormente, ações no Parlamento Europeu.
De acordo com Mark van der Horst (2005), as iniciativas no sentido de uma reforma postal na Europa remontam a 1988, quando os projetos para unificação do mercado postal foram apresentados com contornos mais bem delineados. A primeira iniciativa nesse sentido foi a elaboração, em 1992, do Green paper on postal liberalization ${ }^{3}$. O documento, que convocou os Estados membros a apresentarem as diretrizes para reforma postal, iniciou o debate sobre as mudanças no setor. As contribuições dos países indicaram o caminho a ser seguido, tal como viria a ser empreendido pelo Parlamento Europeu. Três resoluções foram aprovadas e adotadas a partir de então: 
a. o começo imediato da elaboração de propostas para liberalização e desenvolvimento do mercado único;

b. a definição do entendimento acerca de "serviços universais" a serem prestados; e

c. a elaboração de uma definição comum de "atividades que podem ser reservadas".

Segundo Luisa Anderloni e Roberto Pilley (2002), ficou acordado que essas definições seriam as mais restritas possíveis e, ademais, deveriam ser suficientes para suprir os serviços universais com um preço coerente com a natureza do serviço. Assim, buscou-se regulamentar os serviços no sentido de uma abertura postal ao mesmo tempo em que se estabeleciam as reduções dos serviços monopolizados.

Em 1997, depois de mais de três anos de discussões, aprovou-se a Primeira Diretiva postal para os Estados-membros da União Europeia ${ }^{4}$. Por essa Primeira Diretiva, procurou-se harmonizar a legislação e alcançar três principais objetivos, como afirmam Luisa Anderloni e Roberto Pilley (2002: 31):

1. garantir serviços universais com boa qualidade e acessível a todos os usuários, encorajando a abertura mais ampla possível da competição no setor;

2. estabelecer obrigações comuns para todos os prestadores de serviços universais; e

4. A Diretiva é um ato do Parlamento Europeu que obriga todos os Estados membros a cumprirem algumas determinações. Para isso, os Estados têm autonomia política e administrativa. No caso em questão, trata-se da Diretiva 97/67/CE.

3. harmonizar as regras dos serviços universais, as condições de acesso e as regras de qualidade.

De acordo com Mark van der Horst (2005), ao estabelecer como objetivo a abertura de mercado, impôs-se aos países-membros o limite aos serviços monopolizados. Assim, tanto para os serviços nacionais como transnacionais, os objetos postais monopolizados deveriam ter no máximo 350 gramas ou cinco vezes a tarifa básica. Além disso, buscou-se criar órgãos reguladores nacionais.

Com a Primeira Diretiva Postal de 1997, apontou-se a estrutura e os rumos que Estados-membros deveriam seguir. No Quadro 1, a seguir, estão reproduzidas as principais deliberações. Verifica-se que as diretrizes acordadas foram no sentido de garantir um serviço postal universal, o estabelecimento de padrões de qualidade dos serviços internacionais baseado em prazos de entrega e a eliminação gradual do monopólio. Simultaneamente, os operadores postais deveriam estabelecer princípios de gestão condizentes com a transparência atribuída a certos arranjos or- 
QUADRO 1

SÍNTESE DAS DECISÕES ACERCA DO SERVIÇO POSTAL EUROPEU

COM A PRIMEIRA DIRETIVA POSTAL (1997)

\begin{tabular}{|l|l|l|}
\hline \multicolumn{2}{|c|}{ Elementos obrigatórios } & \multicolumn{1}{|c|}{ Elementos opcionais } \\
\hline \multicolumn{1}{|c|}{ Núcleo institucional } & \multicolumn{1}{|c|}{ Ambiente institucional } & \multicolumn{1}{c|}{ Ferramentas disponíveis } \\
\hline $\begin{array}{l}\text { - Serviços universais. } \\
\text { - Padrão de qualidade para } \\
\text { serviços internacionais. } \\
\text { - Limite à área reservada } \\
\text { (monopolizada). }\end{array}$ & $\begin{array}{l}\text { - Tarifas baseadas nos custos. } \\
\text { - Separação do órgão regulador } \\
\text { dos operadores. } \\
\text { - Padrões de qualidade para } \\
\text { serviços nacionais. }\end{array}$ & - Autorizações e licenciamentos. \\
\hline
\end{tabular}

Fonte: Adaptação de Toledano, apud Anderlonni \& Pilley (2002: 31, tradução nossa).

ganizacionais e atuar em um ambiente onde fosse instituído um órgão regulador desvinculado do correio estatal.

Os aspectos discutidos e regulamentados na Primeira Diretiva foram ampliados na "segunda onda" de abertura do mercado postal, em 2002, quando foi aprovada a Segunda Diretiva Postal (Horst, 2005). Essa Segunda Diretiva foi motivada por pressão de grupos empresariais e políticos que se fundamentaram em supostas meIhorias na qualidade do mercado aberto à competição, que estaria mais eficiente, inovador e com melhor qualidade. Para tais grupos, essas melhorias teriam sido possíveis pela adoção de novas tecnologias e por segmentações de mercado que só a competitividade foi capaz de proporcionar (Anderloni \& Pilley, 2002).

Com a adoção da Segunda Diretiva, foi reduzido o monopólio dos correios estatais para objetos postais domésticos com até 100 gramas ou três vezes a tarifa básica a partir de 2003; em 2006, esses valores seriam alterados para 50 gramas, ou duas vezes e meia a tarifa básica.

A Segunda Diretiva postal, segundo Horst (2005), também estabeleceu prazos para a liberalização total, embora tenha deixado a possibilidade de dilatar os prazos para alguns países (Grécia, Portugal, Espanha, Itália, França etc.) caso provassem necessidade em estender o monopólio. Em 2004, com a entrada de dez novos membros na União Europeia e a consequente necessidade de adaptarem suas legislações incluindo a postal-, estabeleceu-se que, até 2006, poderiam usufruir do monopólio dos objetos postais com até 350 gramas ou três vezes a tarifa básica.

A Segunda Diretiva também estabeleceu um "passo decisivo" para análise e revisão dos processos de liberalização e redução/eliminação dos monopólios, bem como uma análise da qualidade dos serviços prestados. Essa revisão foi marcada para 2006, e o prazo para abertura total dos mercados estabelecido para 2009. Todavia, 
em decorrência da impossibilidade de cumprimento dos prazos, a abertura total foi remarcada pelo Parlamento Europeu para ocorrer até 2011 e, para os países membros que ingressaram tardiamente na comunidade, foi estendido o prazo até o final de 2013 para se adequarem às Diretivas (caso, principalmente, dos países do Leste Europeu).

Para evitar distorções nos mercados, os Estados membros que tivessem liberalizado seu mercado poderiam recusar as empresas dos países que ainda operassem sob monopólio em seus territórios.

Para os serviços universais, estabeleceu-se o direito a todos os cidadãos da comunidade à distribuição domiciliária pelo menos uma vez por semana e recolhimento de objetos postais cinco dias por semana (Parlamento Europeu, 2008). Tendo por base essas diretrizes, portanto, o mercado postal da União Europeia foi liberalizado em 2011, tendo alguns países da Europa do Leste conseguido estender esse prazo para o final de 2013.

Verifica-se, a partir do caso específico da União Europeia, que a lógica da integração regional contribuiu com a liberalização postal, mas apenas acelerando o processo, já que foram as diretrizes vinculadas ao ideário neoliberal que orientaram as ações governamentais. Dessa maneira, a "onda de liberalização" postal que se abateu sobre a Europa resulta não somente da integração regional, mas também de escolhas políticas vinculadas à ideologia neoliberal.

\section{Reestruturação de modelos empresariais \\ e corporatização em sistemas postais: análise de casos}

A liberalização gradual dos mercados postais na União Europeia concatena-se aos processos de privatização. Nesse sentido, a regulação do setor foi pensada e formatada para propiciar a entrada e permanência de operadores privados no mercado. Contudo, as opções de cada país mostram que o processo se diferencia conforme as opções dos dirigentes políticos. Nessa direção, verifica-se em relatório da Comissão Europeia que alguns países do bloco optaram por trilhar uma estratégia própria (Brandt, 2007).

Nesse sentido, os 350 anos do correio sueco como órgão da administração pública findaram-se em 1994, quando foi transformado em sociedade anônima e renomeado Posten AB. O objetivo foi retirar todo e qualquer auxílio estatal à empresa, que deveria competir abertamente no mercado. Em 2002 o banco postal foi separado da empresa postal, passando a ser uma empresa à parte. 
Na Holanda, em 1989, o correio foi transformado em empresa pública - a KPN - e, em 1994, em sociedade anônima. Em 1996, a KPN adquiriu a empresa australiana TNT. Em 1998, houve a divisão entre correios e telecomunicações - a PTT correios e a KPN Telecom. Em 2002, por ambições internacionais, tornam-se subsidiárias da TNT Post Group (TPG). Em 2006, a companhia passa a ser TNT Post, que se subdivide em 2011, novamente, em duas: PostNL (correios) e TNT Express (Abvakabo, 2011).

Os serviços postais na Áustria, que até o início da integração do mercado postal europeu eram monopolizados pelo Estado, passaram, a partir de 1988, a ser alvo de propostas de liberalização. Antes disso, no entanto, houve um processo de corporatização do correio estatal, que deixou de ser um departamento da administração direta, a Administração Postal e Telegráfica, para ser transformado em empresa pública: Post und Telekom AG (PTA).

Em 1999 houve a separação dos serviços postais do setor de telecomunicações, o que originou duas empresas distintas. Até 2006, a Post AG ainda era do Estado austríaco, mesmo com a abertura do capital da empresa. Naquele ano, no entanto, o governo austríaco vendeu na bolsa de valores $49 \%$ das ações, permanecendo com $51 \%$ restantes e, por conseguinte, com o controle acionário. A partir de então, a empresa foi fracionada em três, cada qual com atuação em setores distintos de atividade: cartas, encomendas e logística e rede de atendimento (agências, serviços financeiros e comercialização).

Dessa maneira, os serviços postais na Áustria passaram por uma transformação: de um mercado sem competição, transformou-se em um mercado múltiplo e com uma pequena área reservada até 2007 , quando $75 \%$ do mercado foram abertos à competição. Com isso, o operador estatal - Post AG - possuía 98\% do mercado. Contudo, empresas transnacionais como a United Parcel Service (UPS), TNT, Deutscher Paket Dienst (DPD) e Federal Express (Fedex) estão ativas no mercado de encomendas e serviços expressos. Com isso, apesar de a Post AG liderar o setor postal, empresas transnacionais privadas já atuavam visivelmente no mercado austríaco (Brandt, 2007).

O processo de liberalização na Alemanha começou na década de 1980 e já em 1984 as autoridades alemãs abriram o mercado à competição em alguns segmentos. De acordo com Torsten Brandt (2007), em 1989 o Federal Service Postal (Deutsche Bundespost) foi dividido em três companhias estatais: serviços postais (Postdienst), serviços financeiros (Postbank) e serviços de telecomunicações (Telekom). As três companhias tornaram-se legalmente empresas públicas da administração federal e independentes para decisões cotidianas, mas diretamente controladas pelo ministro dos Correios e Telecomunicações. 
Desde 1994 foram empreendidos esforços para privatizar essas empresas e, a partir de 1995, foram transformadas em sociedades de economia mista. Em um primeiro momento, o governo alemão ficou com todas as ações. Com essas mudanças, o serviço postal foi batizado de Deutsche Post AG (DPAG), que, desde 1998, vinha comprando outras empresas.

O passo decisivo rumo à liberalização postal na Alemanha, contudo, resultou da Primeira Diretiva Postal - acompanhando os passos da União Europeia. Em 1998 o país iniciou a formulação da abertura gradual do mercado em conjunto com as diretrizes europeias. Assim, estabeleceu a abertura gradual do mercado até 2007, quando a Alemanha abriu totalmente o mercado.

Antes disso, a partir de 2000, iniciou o processo de corporatização da DPAG - a empresa estatal - com a oferta pública de ações. Nesse ínterim, a empresa foi renomeada para Deutsche Post World Net (DPWN) - empresa holding, com a DPAG como única acionista.

Em 2005, no entanto, investidores privados tornaram-se sócios majoritários da Deutsche Post World Net, comercialmente denominada de Deustsche Post DHL, transnacional líder do mercado global de logística e encomendas expressas. No mercado alemão, somente empresas postais com predominância de capital privado estão presentes. Em 2006, sete empresas dominavam o mercado, formando um oligopólio. De forma direta, portanto, a liberalização postal na Alemanha foi conduzida concomitantemente a uma privatização do correio público (Brandt, 2007).

Na Bélgica, até o início da liberalização postal europeia, também havia poucos competidores no mercado nacional. A abertura comercial do setor naquele país seguiu o cronograma proposto pela União Europeia. Até então, o De Post possuía o monopólio postal e havia sido organizado como empresa pública já em 1991. Desde 2005, no entanto, a participação de acionistas foi autorizada com duas restrições: a participação do Estado belga deveria ser sempre superior a $50 \%$ das ações e estas garantiriam o direito a mais de $75 \%$ dos votos em todas as subsidiárias da empresa.

Apesar disso, desde que a abertura do mercado se iniciou, o número de empresas privadas tem aumentado na Bélgica. Empresas subsidiárias da Deuschte Post Welt Net e TPG Post estão em nichos específicos, sobretudo em segmentos transnacionais de revistas e jornais, de acordo com Torsten Brandt (2007). Há, no entanto, maior competição nos segmentos de encomendas e serviços expressos. Cinco empresas controlam $72 \%$ do mercado, sendo o restante compartilhado por empresas menores. As cinco maiores empresas são as transnacionais DHL, Fedex, TNT e UPS, além da belga Belgium Railway-Subsidiary ABX. Além dessas maiores, há um enorme 
número de empresas menores. Ao todo, quase mil empresas atuam no mercado postal belga, segundo a Comissão Europeia (Brandt, 2007).

No Reino Unido, a principal mudança organizacional, desde 1990, envolveu a transformação das companhias postais em sociedades anônimas já em 2001, sendo o conglomerado denominado, a partir de 2002, de Royal Mail Group. São três operadores postais públicos: Royal Mail (cartas e pequenas encomendas), Parcelforce (encomendas maiores) e Post Office Counters (Agências de Correios), subsidiárias da estatal Royal Mail Holdings.

Apesar da opção por liberalizar vagarosamente o mercado postal, a partir de 2006 o Reino Unido abriu completamente o setor à competição. A despeito da predominância dos correios estatais, havia muitas pequenas empresas que prestavam serviços locais, embora empresas maiores como TNT e DHL também estivessem com boa fatia do mercado de encomendas expressas. As agências de atendimento eram, em sua maioria, franqueadas e, portanto, privadas. Eram mais de 16 mil agências onde se realizavam os mais diversos tipos de serviços. No caso do Reino Unido, a abertura comercial não levou à privatização do operador estatal, mas conduziu ao aumento do número de empresas que competem no mercado de cartas.

Os serviços postais, mesmo depois do início do processo de liberalização no âmbito da comunidade europeia eram prestados, até meados de 2007, predominantemente por correios públicos. A maior participação do operador público pode ser encontrada na Polônia, com 99\% do mercado, enquanto a menor participação do operador público está na Suécia, com 93\% do mercado compartilhado e onde a liberalização total do mercado ocorreu em 1992. Constata-se, como aponta Torsten Brandt (2007), que a Alemanha foi o único país a transferir totalmente aos empresários o setor postal.

Esses casos mostram, assim, que o primeiro passo rumo às privatizações no continente europeu foi a constituição de empresas postais autônomas vinculadas aos Estados e que seguem a lógica público-privada. Ou seja, são criadas empresas públicas com autonomia gerencial, apesar de não estarem sob uma racionalidade concatenada à livre competição e gozarem de benefícios fiscais e reserva de mercado. O segundo passo é a adoção de formas jurídicas privadas associadas à abertura de capital das empresas e a consequente transformação dos operadores públicos em sociedades anônimas. O terceiro e último passo, nesse processo, é a privatização das empresas públicas de economia mista (Anderloni \& Pilley, 2002).

O processo gradual de corporatização tem reformulado os modelos empresariais. De maneira geral, ainda segundo Luisa Anderloni e Roberto Pilley (2002: 18), os modelos organizacionais utilizados nas reestruturações organizacionais podem dividir 
QUADRO 2

REESTRUTURAÇÃO DOS MODELOS EMPRESARIAIS

E CORPORATIZAÇÃO EM PAÍSES SELECIONADOS

\begin{tabular}{|c|c|c|}
\hline País & Ano* & Sentido da reestruturação organizacional e corporatização \\
\hline Japão & 2003 & Empresa estatal $\rightarrow$ privatização $\rightarrow$ divisão em quatro empresas de uma holding. \\
\hline Nova Zelândia & 1987 & $\begin{array}{l}\text { Divisão da New Zealand Post \& Telecommunications em três empresas: Correios } \\
\text { da Nova Zelândia, Banco Postal e Telecom, sendo as duas últimas posteriormente } \\
\text { privatizadas. }\end{array}$ \\
\hline Suécia & 1994 & $\begin{array}{l}\text { Transformado em sociedade anônima. Em 2002, a Posten AB separou-se do Banco } \\
\text { Postal. }\end{array}$ \\
\hline Holanda & 1989 & $\begin{array}{l}\text { Empresa pública (1989) } \rightarrow \text { sociedade de economia mista }(1994) \rightarrow \text { separação } \\
\text { dos correios e telecomunicações (1998) } \rightarrow \text { torna-se subsidiária de multinacional } \\
\text { (2002). }\end{array}$ \\
\hline Alemanha & 1989 & $\begin{array}{l}\text { Dividido em três empresas públicas: correios, telecomunicações e banco postal } \\
\rightarrow \text { sociedades de economia mista (1995) } \rightarrow \text { início da privatização em } 2000 \text {, por } \\
\text { meio de oferta de ações, tornando-se DPWN/DHL } \rightarrow \text { em } 2005 \text {, acionistas privados } \\
\text { tornam-se majoritários da empresa líder do mercado global de logística e enco- } \\
\text { mendas expressas. }\end{array}$ \\
\hline Chile & 1981 & $\begin{array}{l}\text { Foi transformado em empresa pública estatal. Apesar de haver reserva de merca- } \\
\text { do prevista na legislação, a prática concorrencial é de livre mercado. }\end{array}$ \\
\hline Argentina & 1972 & $\begin{array}{l}\text { Criação da empresa pública em } 1972 \rightarrow \text { transformação em Encotesa em } 1992 \rightarrow \\
\text { privatização em } 1997 \rightarrow \text { reestatização em } 2003 \text {, mantendo estrutura de sociedade } \\
\text { anônima com controle estatal. }\end{array}$ \\
\hline Costa Rica & 1998 & Transformado em sociedade anônima em 1998. Permanece sob controle estatal \\
\hline
\end{tabular}

* Ano em que deixou de ser departamento de Estado.

Fonte: Elaboração própria - Dados da União Postal Universal.

o correio estatal em diversas companhias, formando holdings, por exemplo, ou com atuação em segmentos específicos do mercado.

Assim, há um processo concomitante de transformação dos operadores estatais de correios em empresas públicas e, em seguida, a cisão delas em outras empresas ou integrantes de holdings que frequentemente incorporam serviços bancários, seguradoras e telecomunicações.

Da mesma forma, isso também vem ocorrendo fora da União Europeia, como é o caso do Japão. Em 2003, os serviços postais japoneses passaram a ser prestados por uma empresa estatal e pouco depois ela foi privatizada, sendo dividida em quatro empresas que passaram a integrar uma holding.

O mesmo ocorreu anteriormente na Nova Zelândia, quando, em 1987, a New Zealand Post \& Telecommunications foi transformada em empresa pública, sendo dividida, em 1993, em três empresas: Correios da Nova Zelândia, Banco Postal e 
Telecom, sendo as duas últimas privatizadas; já a liberalização postal ocorreu em 1998, com a quebra do monopólio (Brandt, 2007; Anderloni \& Pilley, 2002).

Na América Latina, um dos casos mais emblemáticos é o da Argentina. Em 1972 foi criada a Empresa Nacional de Correos y Telégrafos (Encotel), responsável pelos serviços postais daquele país. Em 1992, como parte dos processos de modernização do setor, foi transformada na Empresa Nacional de Correos y Telégrafos S.A. (Encotesa), que atuou até 1997 como empresa pública, quando foi privatizada como parte das políticas de ajuste estruturais de matiz neoliberal por que passava o país. Em 2003, contudo, como parte da diminuição da influência do receituário neoliberal e da crise que permanecia no setor postal, a empresa foi reestatizada e denominada de Sociedad Correo Oficial de la República Argentina S.A. (Corasa). Importante destacar que a Corasa se manteve como empresa de sociedade anônima, não sendo alterado, mesmo com a reestatização, o processo de corporatização.

No Brasil, a criação da ECT como empresa pública em 1969 para atuar no setor postal foi algo pioneiro no que concerne aos processos de corporatização. Durante a década de 1990, o governo de Fernando Henrique Cardoso apresentou o projeto da Nova Lei Postal, visando criar o Sistema Nacional de Correios. Com isso, haveria a liberalização gradativamente do mercado postal, a atuação de empresas privadas no setor, a criação de uma agência reguladora e o aprofundamento da corporatização do operador público com a criação da Correios do Brasil S.A. Com o malogro da proposta, a estatal brasileira, contudo, passou a ser regida também pela Lei das Sociedades Anônimas no governo Dilma Rousseff, embora com capital integralmente da União, o que aprofundou o processo de corporatização da ECT (Teixeira, 2013).

O serviço postal na Costa Rica, por sua vez, que funcionou até 1998 organizado como departamento de Estado, foi transformado em corporação em 1998, passando a se chamar Correos de Costa Rica S.A. Desde então, o operador estatal do país funciona regido pelo direito privado, permanecendo, contudo, como propriedade estatal e atuando em um mercado aberto à competição. O operador estatal, contudo, tem buscado monopolizar fatias do mercado postal como forma de assegurar sua sustentação financeira.

Ao contrário do que é propalado pelas agências multilaterais, as mudanças têm provocado processos graduais de concentração de mercado, isto é, há uma tendência à formação de oligopólios no mercado postal, sobretudo entre grupos postais transnacionais como DHL e Fedex. A formação de oligopólios, em tese, deveria ser evitada pela regulação independente por meio de agências autônomas. No entanto, a concentração de mercado pelas grandes empresas de courier tem prevalecido nos países onde as mudanças estão ocorrendo. 


\section{Transformações na esfera do trabalho: reestruturação operacional e redução dos postos de trabalho}

As transformações nos sistemas postais têm atingido os processos de trabalho e o volume de empregos no setor.

O impacto das transformações sobre o trabalho e o emprego no setor postal tem seguido também certa lógica processual: antes da liberalização propriamente dita, iniciam-se processos de reestruturação operacional, automatização e mecanização de atividades, que podem ser concomitantes ou posteriores aos processos de corporatizaçao. Com a corporatização, os contratos de trabalho deixam de ser regidos pelo estatuto do funcionalismo público e passam a ser regidos pelo direito privado. Isso proporciona flexibilidade administrativa para o corte dos postos de trabalho eliminados nos processos de reestruturação e automatização.

Nesse sentido, a automatização de processos de trabalho, reestruturação de serviços operacionais e de distribuição, redução de rotas de distribuição e diminuição do número de agências próprias do operador estatal, dentre outras medidas, são estratégias adotadas pelas empresas postais que têm impactado a qualidade e quantidade dos empregos no setor, como os estudos de caso encomendados e apresentados pela Uni Global Union (2009), federação sindical, evidenciam.

Conforme as reestruturações avançam, mudanças têm sido introduzidas nos processos de atendimento, encaminhamento, triagem e distribuição postal. A triagem dos objetos postais, etapa intermediária entre a captação e a distribuição dos objetos postais, tem sido um dos principais alvos de automatização. Os operadores postais na União Europeia têm buscado introduzir processos automatizados de triagem como meio de redução dos custos com mão de obra e como forma de incrementar a produtividade (Teixeira, 2013). A redução dos custos com a força de trabalho é mesmo considerada como o principal motivo para investimentos na automação. Além disso, possíveis ganhos de qualidade e celeridade ao processo são citados como motivos para investimentos nessas tecnologias, de acordo com a Comissão Europeia (PLS Ramboll, 2002).

Assim, a busca pela flexibilidade, pela redução de custos nas operações e pelo aumento da produtividade têm levado os operadores postais, sobretudo na União Europeia, a reestruturações nas rotinas operacionais (Anderloni \& Pilley, 2002).

O caso sueco é significativo dos rumos das transformações nos centros de distribuição. De acordo com Anette Erlandsson (2002), a liberalização do mercado e a 
reestruturação do sistema postal na Suécia conduziram à reestruturação dos processos operacionais do agente público. A reestruturação foi realizada por meio de um programa implantado em 2000 e denominado Best method. O objetivo central do programa foi otimizar o processo de trabalho por meio da introdução de métodos de trabalho baseados na flexibilidade organizacional e no tempo para execução das atividades de trabalho. O programa teve como principais resultados a padronização dos procedimentos e a formalização do tempo de entrega. Houve, segundo a autora, a racionalização dos procedimentos de trabalho, o que resultou em uma intensificação do trabalho pelo maior volume de objetos postais direcionados às unidades operacionais e a redução da participação dos trabalhadores na concepção de suas atividades de trabalho.

Os cortes drásticos de postos de trabalho no setor têm atingido todas as etapas dos processos de trabalho, notadamente no atendimento em agências, na triagem em unidades intermediárias e na distribuição postal.

Nesse sentido, verifica-se que na União Europeia, onde trabalhavam 1,94 milhão de pessoas no setor postal, em 2006, tem havido uma enorme mudança nos padrões de trabalho, sobretudo com a redução do número de empregos, segundo relatório da Fundação Europeia para a Melhoria das Condições de Vida e Trabalho (Eurofound, 2007).

Nessa direção, é possível observar que, na Alemanha, entre 1990 e 2001, o volume de negócios aumentou em 350\%, enquanto um corte em massa de postos de trabalho era realizado no setor. Durante esse período, de acordo com a Comissão Europeia (Brandt, 2007), a redução foi de 160 mil posições de trabalho. Se for considerado apenas o intervalo entre 1999 e 2006, a redução de empregos em tempo integral foi de mais de 21 mil, ao tempo em que a redução dos postos com jornada parcial foi de 12 mil (Uni Global Union, 2009). Houve, assim, uma redução drástica do volume de empregos no setor postal naquele país: em torno de $30 \%$, segundo Elbert Dijkgraaf e Frans van der Zee (2009).

5. Os dados de outros países corroboram a tendência mundial de redução de postos de trabalho no setor, segundo o relatório da Eurofound (2007), que ainda afirma que houve o corte de empregos em torno de $30 \%$ na Noruega, na Itália e em Malta.
Na Áustria, a redução de empregos em tempo integral no Post AG também foi considerável. Se em 2001 esses trabalhadores eram mais de 30 mil, em 2005 eram pouco mais de 25 mil, segundo a Comissão Europeia (Brandt, 2007). Conforme a Eurofound (2007), os cortes de empregos na Áustria foram de cerca de $22 \% 5$.

Na Holanda, a PostNL, por exemplo, reduziu seus funcionários com jornada integral de 25 mil em 2005 para 16 mil em 2010 e, ao mesmo tempo, ampliou o efetivo com jornada parcial de seis mil para 13 mil entregadores (Abvakabo, 2011). 
Dessa forma, como argumentam Elbert Dijkgraaf e Frans van der Zee (2009), os cortes nos postos de trabalho no setor postal internacional, invariavelmente, têm sido ampliados.

Na Argentina, de cerca de 40 mil trabalhadores que trabalhavam na triagem de objetos postais em 1997, restaram cerca de 32 mil, isso com considerável aumento do volume de tráfego postal. Com a reestatização, contudo, os postos de trabalho no setor postal voltaram a crescer (Uni Global Union, 2009).

O corte de empregos, conforme expõe o relatório da Comissão Europeia sobre o setor postal (Brandt, 2007), envolve a flexibilização dos contratos trabalhistas para os trabalhadores que permanecem no setor, aumentando consideravelmente o número de contratos parciais e atípicos, com trabalhadores ganhando por hora. E isso impacta diretamente a capacidade de organização dos trabalhadores e a capacidade de negociação dos sindicatos. Para a Uni Global Union, esses processos desencadeiam

[...] uma diminuição crescente do poder sindical, uma fragmentação das estruturas de negociação e, por conseguinte, do emprego e das condições salariais dos antigos operadores postais estatais. [...] Em vários setores e países, os novos operadores postais não estão incluídos nos acordos coletivos, sendo beneficiados por normas de empregos inferiores [salários mais baixos e jornadas de trabalho maiores ou mais flexíveis] (Piquet apud Uni Global Union, 2009: 15, tradução nossa).

Diante desses aspectos, verifica-se que as transformações nos sistemas postais tiveram um impacto direto sobre o trabalho e o volume de empregos no setor. As reestruturações e automatizações têm degradado as condições de trabalho e, juntamente com a corporatização e privatização dos operadores estatais, atuado na redução de postos de trabalho. A precarização do trabalho é a outra face do processo, com mudanças nos contratos de trabalho restantes por meio da ampliação de formas atípicas de contratação (trabalho em tempo parcial, pagamento por jornada etc.), o que tem enfraquecido o poder sindical de negociação e reverberado na degradação do trabalho no setor.

\section{Considerações finais}

O mapeamento das transformações no setor postal internacional revela um cenário de mudanças radicais. Os fatores que têm motivado tais transformações são múltiplos, mas destacam-se os seguintes:

1. a emergência de grupos privados no setor de transportes e comunicações; 
2. o lobby de grupos de operadores postais privados (courier), que pressionam para que os segmentos monopolizados sejam reduzidos ao máximo;

3. as orientações de agências e instituições como Banco Mundial e Fundo Monetário Internacional, que exigiam programas de "ajustes estruturais" dos países para maior espaço ao capital privado e menor intervenção estatal, isto é, a implementação da lógica neoliberal; e

4. os mecanismos de integração dos mercados regionais na União Europeia.

As transformações, em um primeiro momento, transferem de uma lógica pública para a privada os sistemas de correios, quase sempre assumindo a forma de empresas públicas. Isso tem sido um dos primeiros passos no processo gradual de privatização, pois possibilita a introdução de novas formas de administração concomitantemente à preparação da abertura de mercado e possível privatização do correio estatal. Trata-se, em suma, de um processo de corporatização que precede processos de privatização.

O que se observa, portanto, é um continuum entre a proposta das agências multilaterais para "modernizar" o setor postal mundial e as mudanças efetivas, sobretudo em relação aos processos de liberalização pari passu às reformas organizacionais dos correios tradicionais (estatais). Esses processos, de maneira geral, têm resultado em privatizações ou, pelo menos, na venda de ações das empresas postais.

Assim, pode-se concluir que a liberalização postal se associa às privatizações e à abertura do capital das empresas estatais sob a justificativa da modernização gerencial.

A criação de agências reguladoras - recomendação de organismos multilaterais como Banco Mundial e OCDE - tem sido realizada para organizar e estabelecer as condições de operação em mercados postais abertos. Caberia às agências reguladoras garantir uniformidade e igualdade no tratamento às empresas no mercado competitivo e na prestação de serviços universais obrigatórios. A regulação do mercado postal aberto teve como premissa, em linhas gerais, a competitividade entre operadores, a qualidade dos serviços prestados, os valores das tarifas e as normas trabalhistas.

A regulação postal no contexto da União Europeia tem sido realizada por meio de diferentes instrumentos, dentre os quais o próprio poder público, mediante regras, normas e padrões para prestação dos serviços por contratos e por agências 
reguladoras autônomas. Ao aprovar Diretivas para liberalização do setor, ficou garantida a autonomia para cada Estado-membro decidir entre agências reguladoras ou pelos próprios ministérios estatais.

A regulação do mercado postal tem sido realizada de diferentes maneiras no contexto europeu, com variados desempenhos dos órgãos reguladores. No entanto, a regulação estatal tem sido mais eficiente do que as agências autônomas, porque a capacidade de atuação destas é limitada. De forma paradoxal, apenas no mercado postal da Alemanha - que foi um dos primeiros a liberalizar o mercado -, as condições de trabalho são elementos examinados pelas agências reguladoras ao concederem ou renovarem o licenciamento das empresas postais.

Contudo, observa-se nos países que implementaram as reformas na direção da liberalização e das privatizações uma crescente concentração de mercado, com a formação de oligopólios por grandes transnacionais, evidenciando que as agências reguladoras, quando adotadas, não asseguram, per si, barreiras à concentração de mercado.

No que concerne à esfera do trabalho, verificam-se crescentes reestruturações dos processos operacionais relacionados ao atendimento em agências e na automatização dos processos de triagem nos centros de triagem e distribuição domiciliária. São processos focados em crescentes racionalizações e incorporações tecnológicas.

A distribuição domiciliária, por sua vez, tem sido impactada pela crescente e radical redução dos postos de trabalho. A mudança nos regimes de contratação - de regime dos funcionários estatais para contratos regidos pelo direito privado - está associada à redução salarial.

Dessa forma, a tendência do trabalho nos países que privatizaram seus sistemas postais tem sido a degradação das condições de trabalho e a precarização dos vínculos trabalhistas, com uma redução maciça de postos de trabalho no setor.

Abstract: The aim of this article is to analyze the trends of the postal system on the international scene with a focus on market regulation mechanisms and the restructuring of the organizational models of public operators towards corporatization and privatization, showing the impact on the sphere of work. The article was developed through a documentary and bibliographic research and secondary data of the Universal Postal Union. For this, were compiled and analyzed reports produced by multilateral organizations and regional blocks. Among the main findings, there is the liberalization of postal markets as the predominant tendency associated with gradual processes of market concentration and consequent formation of oligopolies, mainly by transnational groups. The postal liberalization has been accompanied by organizational restructuring and privatization 
of state-owned operators proceedings under the justification of administrative modernization. Furthermore, there are increasing operational restructuring and concomitant job precariousness and increase reduction of jobs in the sector.

Keywords: postal systems, postal liberalization, regulation, organizational restructuring, employment reduction.

\section{Referências}

ABVAKABO. We underestimated the consequences of postal liberalisation. Uni Global Union. Read News, 07 Maio 2011. Disponível em: <http://www.uniglobalunion.org/news/abvakabo-we-underestimated-consequences-postal-liberalisation>. Acesso em: 15 jan. 2016.

ANDERLONI, Luisa; PILLEY, Odile. Changing context for postal systems in Europe. In: RUOZI, Roberto; ANDERLONI, Luisa (Orgs.). Modernisation and privatisation of postal systems in Europe. Berlin; Heidelberg: Springer, 2002.

ANDERSON, Perry. Balanço do neoliberalismo. In: SADER, Emir; GENTILI, Pablo (Orgs.). Pós-neoliberalismo: as políticas sociais e o Estado democrático, p. 9-23. Rio de Janeiro: Paz e Terra, 1995.

ANTUNES, Ricardo. A desertificação neoliberal: Collor, FHC, Lula. Campinas: Autores Associados, 2004.

- Os sentidos do trabalho: ensaio sobre a afirmação e a negação do trabalho. São Paulo: Boitempo, 1999.

BRANDT, Torsten. Liberalisation, privatisation and regulation of postal services in Europe. Piquet discussion paper. Düsseldorf: European Comission, 2007. Disponível em: <http://www.boeckler.de/pdf/wsi_pj_piq_post_europe.pdf>. Acesso em: 15 Jan. 2016.

CASTEL, Robert. As metamorfoses da questão social. Petrópolis: Vozes, 1999.

CASTELLS, Manuel. A sociedade em rede. A era da informação: economia, sociedade e cultura. São Paulo: Paz e Terra, 2005.

CREW, Michael; KLEINDORF, Paul (Orgs.). Regulatory and economic challenges in the postal and delivery sector. New York: Springer Science, 2005.

DIJKGRAAF, Elbert; ZEE, Frans van der (Orgs.). Investing in the future of jobs and skills: post and telecommunications. Bruxelles: European Commission, 2009. 
ERLANDSSON, Anette. A top-down rationalisation in mail delivery-short-term outcomes. Work Intensity Conference. Paris 21-22 Nov. 2002.

EUROFOUND. European Foundation for the improvement of living and working conditions, industrial relations in the postal sector. Dublin: Eurofound, 2007. Disponível em: <http://www.eurofound.europa.eu/sites/default/files/ef_files/docs/eiro/ tn0704018s/tn0704018s.pdf>. Acesso em: 16 Jan. 2016.

HARVEY, David. Breve historia del neoliberalismo. Madrid: Ediciones Akal, 2007.

HORST, Mark van der. Postal liberalisation in the EU: a small step in weights, a giant leap for the market. In: CREW, Michael; KLEINDORF, Paul (Orgs.). Regulatory and economic challenges in the postal and delivery sector. New York: Springer Science, 2005.

LEAVEY, Thomas E. Introductory statement. In: RANGANATHAN, Kumar; DEY, Rohini. Redirecting mail: postal sector reform. Washington DC, 1996. Disponível em: <http://documents.worldbank.org/curated/en/1998/06/693346/redirecting-mail-postal-sector-reform>. Acesso em: 24 Jan. 2016.

MATAIS, Andreza. Correios têm prejuízo superior a R\$ 800 milhões com remessa de cartas. O Estado de S. Paulo, Economia B10. 18 Jan. 2014.

ORGANIZAÇÃO PARA COOPERAÇÃO E DESENVOLVIMENTO ECONÔMICO (OCDE). Promoting competition in postal services. policy roundtable. Paris: OCDE, 1999. Disponível em: <http://www.oecd.org/regreform/sectors/1920548.pdf>. Acesso em: 15 Jan. 2016.

PARLAMENTO EUROPEU. Comunicado de Imprensa: Abertura dos serviços postais à concorrência em 2011, 31 Jan. 2008. Disponível em: < http://www.europarl.europa.eu/sides/getDoc.do?pubRef=-//EP//TEXT+IM-PRESS+20080130IPR20129+0+DO$\mathrm{C}+\mathrm{XML}+\mathrm{VO} / / \mathrm{PT}>$. Acesso em: 26 Set. 2011.

POSTAL Services. The EU single market. 2013. Disponível em: <http://ec.europa.eu/ internal_market/post/index_en.htm>. Acesso em: 29 Ago. 2013.

PLS RAMBOLL. Employment trends in the EU postal sector: final report. Bruxelles: European Comission, 2002. Disponível em: <http://ec.europa.eu/internal_market/ post/doc/studies/2002-employment-report_en.pdf>. Acesso em: 16 Jan. 2016.

RANGANATHAN, Kumar; DEY, Rohini. Redirecting mail: postal sector reform. Washington (DC), 1996. Disponível em: <http://documents.worldbank.org/curated/ en/1998/06/693346/redirecting-mail-postal-sector-reform>. Acesso em: 15 Jan. 2016. 
UNI GLOBAL UNION. Post \& Logistic. What has postal liberalization delivered? Nyon (Suíça): Uni Global Union, 2009. Disponível em: <http://www.africaefuture. org/files/ssanipost/UNI\%20P\&L\%20Research\%20on\%20Liberalisation.pdf>. Acesso em: 15 Jan. 2016

TEIXEIRA, Tadeu Gomes. Os correios em transformação: reestruturação, organização do trabalho e políticas de gestão do trabalho (1994-2011). Tese (Doutorado em Ciências Sociais) - Instituto de Filosofia e Ciências Humanas, Universidade Estadual de Campinas, Campinas, 2013. 